TENTH WARREN K. SINCLAIR KEYNOTE ADDRESS

\title{
THE FUKUSHIMA NUCLEAR POWER PLANT ACCIDENT AND COMPREHENSIVE HEALTH RISK MANAGEMENT
}

\author{
Shunichi Yamashita* \\ * Radiation Medical Science Center for the Fukushima Health Management Survey, Fukushima Medical \\ University, 1 Hiragaoka, Fukushima 960-1295, Japan and Atomic Bomb Disease Institute, Nagasaki \\ University, 1-12-4 Sakamoto, Nagasaki 852-8523, Japan \\ Phone: +81-(0)95-819-7116 \\ Fax: +81-(0)95-819-7117 \\ Email: shun@nagasaki-u.ac.jp
}

For correspondence contact the author at the above address, or email at shun@nagasaki-u.ac.jp 
Abstract -Just 2 y have passed since the Tokyo Electric Power Company-Fukushima Daiichi Nuclear Power Plant (NPP) accident followed a multidimensional disaster that combined to destroy the local infrastructure on which the safety system depended, and gave a serious impact to the world. Countermeasures including evacuation, sheltering, and control of the food chain were implemented in a timely manner by the Japanese government. However, there is a clear need for improvement, especially in the areas of nuclear safety and protection, and also on the management of the radiation health risk during and even after the accident. To date there have been no acute radiation injuries. The radiation-related physical health consequences on the general public, including evacuees, are likely to be much lower than those arising from the Chernobyl nuclear reactor accident, because the radiation fallout and the subsequent environmental contamination were much more limited. However, the social, psychological, and economic impacts of the Fukushima NPP accident are expected to be considerable. Currently continued monitoring and characterization of the levels of radioactivity in the environment and foods in Fukushima are vital for obtaining the informed consent to the decisions on living in the areas already radiocontaminated and also on returning back to the evacuated areas once permitted for re-entrance; it is also important to perform a realistic assessment of the radiation doses on the basis of measurements. We are currently implementing the official plans of the Fukushima Health Management Survey, which includes the basic survey for the estimation of the external doses that were received during the first 4 mo after the accident and four detailed surveys: thyroid ultrasound examination, comprehensive health check-up, mental health and life-style survey, and survey on pregnant women and nursing mothers, with the aim to prospectively take care of the health of all of the residents of the Fukushima Prefecture for a long time.

Key words: National Council on Radiation Protection and Measurements; Fukushima; Chernobyl; internal exposure; thyroid cancer; health effects 


\section{INTRODUCTION}

This is my second presentation at a National Council on Radiation Protection and Measurements annual meeting. My first presentation, which was made in 2006 in commemoration of the $20^{\text {th }}$ anniversary of the Chernobyl nuclear reactor accident, was focused on the World Health Organization (WHO) Chernobyl projects from the standpoint of "Public Perception of Risks, Rehabilitation Measures, and Long-Term Health Implications of Nuclear Accidents" (Yamashita et al. 2007). At that time, I emphasized that the uncertainty of low-dose radiation effects makes it difficult to communicate the risk to the public through our onsite experience around Chernobyl, where we had been continuously working since 1991 in the framework of the Chernobyl Sasakawa Medical Cooperation Project (Yamashita 1997). One of our conclusions, was that public perception of radiation risks, even when physical findings are available, is easily influenced by other sources of information such as the mass media and groundless rumors. Second, during the recovery and rehabilitation period after the Chernobyl nuclear reactor accident, unnecessary threat of radiation as well as over- and under-estimation of radiation risk among the residents of affected areas should be avoided.

Maternal concern is, however, the most serious and important, especially for their children's health and future. Indeed, thyroid cancer risk is well known to increase not only due to external exposure but also through internal exposure to radioactive iodine. Both are particularly important to the understanding of health effects (Ron 2002; Ivanov et al. 2012; Ron et al 2012) (Fig. 1). In addition, thyroid blocking with suitable prior medication of a stable iodine tablet needs to be prepared for reduction and prevention of the internal exposure to radioactive iodine immediately after such an accident, and the safety control of food (e.g., abandoning the polluted original mile) needs to be put into practice as well. One of the most important lessons learned from the Chernobyl nuclear reactor accident was to avoid the initial exposure to radioactive iodines released from nuclear accidents thus reducing or preventing the increase of radiationassociated childhood thyroid cancers around Chernobyl. Of course, psychosocial and mental health 
consequences, including post-traumatic stress syndrome are very important issues to be solved (WHO 2006).

From the Fukushima Nuclear Power Plant (NPP) accident, a variety of problems were exposed in the initial response, which will be evaluated. In particular, the re-examination of evacuation preparation area, the predistribution of stable iodine tablets, the transmission of information to the public after an accident, the re-examination of public risk communication, and the development of an optimal guideline for the revival and restoration after the accident are necessary. Fortunately, there have not been any persons with acute radiation syndrome in Fukushima, and it is very unlikely that hypothyroidism will develop as a result of deterministic effect. In addition to lessons learned from the Chernobyl nuclear reactor accident, we should share our important experience in Fukushima; the knowledge and training in preparation and response to a NPP accident, understanding of the present condition of Fukushima, and also the long-term observation of health. In particular, the regular and accurate evaluation of the thyroid gland is required with regard to public radiation risk awareness and perception. Although Chernobyl and Fukushima are different, there are many similarities especially regarding radiation fear and post-accident psychosocial and mental impacts.

On a basis of the above background, at the special honorable occasion of the Tenth Annual Warren K. Sinclair Keynote Address, in the first part of my presentation, our own experience and knowledge on the Chernobyl nuclear reactor accident, especially radiation risk of childhood thyroid cancer will be focused on as an useful source of rehabilitation and revival for Fukushima (Balonov 2013). Then in the second part of my presentation, our recent progress of the Fukushima Health Management Survey projects will be summarized and discussed to seek for the future direction of appropriately well-balanced radiation risk management in Fukushima. 


\section{LESSONS LEARNED FROM THE CHERNOBYL NUCLEAR REACTOR ACCIDENT}

On the early morning of 26 April 1986, an explosion accident occurred at the Chernobyl NPP Power Unit No. 4 ("high power channel-type reactor," a water-cooled, graphite-moderated nuclear power reactor) located in the former Soviet Union (currently in Ukraine). The nuclear reactor and the reactor building were destroyed by the accident, and subsequently fires broke out in many places due to the scattering of hot black lead. Large scale of radioactive material continued to release until 6 May. The main radioactive materials emitted in the environment were ${ }^{131} \mathrm{I},{ }^{134} \mathrm{Cs},{ }^{137} \mathrm{Cs},{ }^{95} \mathrm{Nb},{ }^{144} \mathrm{Ce},{ }^{103} \mathrm{Ru},{ }^{106} \mathrm{Ru},{ }^{90} \mathrm{Sr},{ }^{239} \mathrm{Pu}$, and ${ }^{240} \mathrm{Pu}$, which reached a total amount of $14 \mathrm{EBq}$. Although strontium and plutonium, which were included into large particles, deposited on the ground surface within a distance of $<100 \mathrm{~km}$ from the nuclear plant, other radioactive materials were widely diffused in the Northern Hemisphere around Europe (Saenko et al. 2011).

Immediately after the Chernobyl nuclear reactor accident, external exposure became a problem for workers who were in the NPP or nearby in the high dose area, whereas internal exposure became a problem for the residents nearby who were exposed to indirect radioactive fallout. Acute radiation syndrome-related health consequences including the number of deaths have been summarized by the United Nations Scientific Committee on the Effects of Atomic Radiation (UNSCEAR 2011).

In particular, critical problems for the local residents arose as a result of contamination of ${ }^{131}$ I was found in milk derived from cows that ate grass contaminated with ${ }^{131} \mathrm{I}$ in the surrounding area of Chernobyl. Due to insufficient and inappropriate restriction on distribution and ingestion of the ${ }^{131} \mathrm{I}$ contaminated milk by the government officials, people continued to consume it, particularly children of Belarus, Russia, and Ukraine of the former USSR during the era of the cold war. Iodine has the property to be selectively taken in by thyroid gland, which also applies to ${ }^{131} \mathrm{I}$. In addition, Chernobyl is an inland area and an area that lacks iodine, which became the contributive factor exacerbating the thyroid internal exposure of children who ingested ${ }^{131}$ I contaminated milk (Cardis et al. 2005). It is estimated that these children received thyroid equivalent doses ranging up to several thousand millisieverts. As a result, it has 
been reported that infant thyroid cancer (papillary adenocarcinoma) started, $\sim 5 \mathrm{y}$ after the accident, to increase rapidly in people who were children (especially 0-5 y of age) at the time of the accident (Kazakov et al. 1992; Likhtarev et al. 1995). The risk of childhood thyroid cancer has also been reported epidemiologically by ingested ${ }^{131} \mathrm{I}$ just after the Chernobyl nuclear reactor accident both in Belarus and in the Ukraine (Jacob et al. 2006; Brenner et al. 2011; Zablotska et al. 2011). So far the number of cases $25 \mathrm{y}$ after the accident has amounted to $\sim 6,000$ people (UNSCEAR 2011). The peak of the present thyroid cancer has shifted to the adulthood in three affected countries (Fig. 2). Although the detailed carcinogenic molecular mechanism is being examined, no clear radiation-associated signature genes have been proven (Saenko and Yamashita 2010). The clinicopathological characteristics of radiation-associated thyroid cancers have been clarified including age-dependent changes of different histotypes of papillary thyroid carcinomas and genetic alterations (e.g., age-dependent frequencies of $R E T / P T C$ rearrangement or $B R A F$ mutations (Fig. 3). Interestingly enough, common genetic variants (single nucleotide polymorphisms) have been proven to be largely overlapping in the surrounding area of Chernobyl (Takahashi et al. 2010) with single nucleotide polymorphisms underlying susceptibility to thyroid cancer in the European population (Gudmundsson et al. 2012). The molecular mechanism of radiation-induced thyroid carcinogenesis has been also reviewed from the standpoint of radiation genetics and biology (Yamashita and Saenko 2007; Suzuki and Yamashita 2012).

On the other hand, the physical half-life of ${ }^{131} \mathrm{I}$ is $\sim 8 \mathrm{~d}$ and it decays quickly out of the environment, but it is the radioactive cesium that remains. The physical half-lives of ${ }^{134} \mathrm{Cs}$ and ${ }^{137} \mathrm{Cs}$ are $\sim 2 \mathrm{y}$ and $30 \mathrm{y}$, respectively. Radioactive cesium was highly contaminated among animals and plants in the forest as the cycle of the food chain was polluted with it. High levels of ${ }^{137} \mathrm{Cs}$ were detected in mushrooms, grapes, and meat $20 \mathrm{y}$ after the accident, and internal exposure continues through ingestion in parts of Belarus, Ukraine, and Russia (Hayashida et al. 2011).

However, in the report of the Chernobyl Forum published jointly by the International Atomic Energy Agency (IAEA) and WHO, $20 \mathrm{y}$ after the accident, only infant thyroid cancer is accepted as a health effect based on the radiation after the Chernobyl nuclear reactor accident. Other malignant tumors, leukemia, 
and other health effects were not increased as a result of radiation exposure (IAEA 2006). Moreover, a difference was not seen in the rate of the incidence of congenital abnormality between cesium contaminated areas and noncontaminated areas. The Chernobyl Forum Report specified that the greatest health problem due to the accident were the mental and psychosocial issues.

\section{RADIATION PHOBIA AS A GLOBAL ISSUE}

In terms of basic data on radiation on health, the Radiation Effects Research Foundation's long-term survey study data on atomic-bomb survivors is the most precise for assessment of external radiation exposure and cancer death rates. The painfully tragic atomic bombing contributed to the accumulation of scientific knowledge and the creation of UNSCEAR that sponsors reviews every few years on the sources and effects of ionizing radiation. In addition, atomic-bomb survivor follow-up studies have formed the bedrock of International Commission on Radiological Protection (ICRP) activities. The ICRP has worked since before the war toward standards and policy proposals for nuclear safety, such as workplace regulations regarding radiation exposure. The IAEA received policy proposals based on this scientific knowledge and formulated its Basic Safety Standards. Each country including Japan has devised, on the basis of these recommendations, nuclear safety measures according to their individual circumstances.

However, listening to the discussions and debates on radiation exposure risks since the Fukushima NPP accident to date, it appears that the international standards, which use the linear no-threshold (LNT) cancer risk model, are being established from the standpoint of radiation protection but do not reflect the real health risks themselves. In particular, the meaning of LNT model and biological effect of low dose radiation exposure have been insufficiently understood. Thus, an inadequate understanding of radiation biology has been exposed.

Ironically, the lack of information created a glut of information, so called "Information Disaster" or "Information Contamination" to the public concerning a low dose and low-dose rate radiation health risk. This resulted in the entire populace losing trust in the experts and a prolonged "radiation phobia." It is 
really sad and unfortunate that before Fukushima NPP accident, in Japan almost nobody knew about the international framework of radiation protection and safety, even the names of UNSCEAR and ICRP. Furthermore, there is a scarcity of real experts in radiation protection and medical professionals on radiation health risk management. Although the causes of radiation phobia have long been debated at international conventions, in light of the nuclear conflict presumed by the East-West Cold War era and especially in the middle of a myth of nuclear safety in Japan bearing the negative consequences of atomicbomb suffering, the confusion brought on by the Chernobyl nuclear reactor accident, and the recent post9/11 nuclear terrorism countermeasures, propagation of radiation phobia in times of emergency is a worldwide issue. Fear and anxiety, even anger toward radiation and radioactivity can cause a wide range of health issues. For this very reason, proper risk communication at ground zero is an integral part of quality health care.

\section{FUKUSHIMA NPP ACCIDENT AND DOSE EVALUATION}

All the nuclear reactors of the first and second Tokyo Electric Power Company NPPs in Fukushima stopped automatically after the Great East Japan Earthquake on 11 March 2011. However, although continuous cooling is needed for the nuclear fuel and spent nuclear fuel in a nuclear reactor or a spent nuclear fuel pool for the decay to remove heat it generates, all the power supplies of reactors No.1-4 only at the first Fukushima NPP for cooling were completely lost due to the earthquake and tsunami. Hydrogen explosion and destruction of the buildings happened in succession with the result that a lot of radioactive materials were emitted to the environment, and spread by the wind. Except for the NPP workers and the members of the public responsible for the security and administration of the $20 \mathrm{~km}$ radius, almost all residents near the NPP were evacuated, as a result of instructions from officials, to distances beyond $2 \mathrm{~km}$, $3 \mathrm{~km}$ (11 March), $10 \mathrm{~km}$, and finally $20 \mathrm{~km}$ (12 March) from the first Fukushima NPP site.

The body surface radioactive contamination screening for the evacuees of Fukushima Prefecture started on 13 March. It was necessary to increase the whole-body decontamination screening cutoff value 
to $100,000 \mathrm{cpm}$ with the Geiger-Mueller survey meter (diameter of $5 \mathrm{~cm}$ ) on and after 15 March because of difficult situation of decontamination for each evacuee under a shortage of washing water and very cold weather condition without any clothes for changing. Radioactive material spread from NPP to the northwest through the southeastern wind on the afternoon of 15 March, and high dose rates in air of $\sim 10$ $20 \mu \mathrm{Sv} \mathrm{h}^{-1}$ were measured in Fukushima city, $\sim 60 \mathrm{~km}$ from the NPP. According to the environmental measurement data in Fukushima, radioactive material dispersed by the wind after the hydrogen explosion contaminated the surface. Later it became clear that Iitate-village (mura) had suffered from a high level of radiation fallout from 15 March at least for $1 \mathrm{wk}$ (Fig. 4). During those days, however, no accurate information was released from the Japanese government. The main radioactive nuclide emitted from the NPP was ${ }^{131}$ I with short physical half-life of $\sim 8 \mathrm{~d}$, and the area measured with high dose rate in air at that time also showed an immediate declining trend. Among the radionuclides emitted from the same NPP, ${ }^{134} \mathrm{Cs}$ and ${ }^{137} \mathrm{Cs}$ will have long physical half-lives. These were deposited on soil, roofs, and on outer walls of buildings where they will remain for a long time.

Shipment and ingestion restrictions of food concerning radioactive iodine and the amount of cesium began with the milk of Fukushima Prefecture and the spinach of Fukushima, Ibaraki, and Tochigi Prefectures on 2 March. The safe interim standard value on food that causes a maximum annual internal dose of $5 \mathrm{mSv}$ was set at the end of March 2011, and the shipment restriction and ingestion restrictions on food exceeding the value were conducted. In April 2012, 1 y after the accident, the maximum annual internal dose was reduced to $1 \mathrm{mSv}$ because of the stabilization of the NPP.

Unfortunately, based on the weather survey data, radiation data, and the information of radioactive material discharge immediately after the accident, wind velocity, and the System for Prediction of Environmental Emergency Dose Information (SPEEDI), which was scheduled to predict and calculate the air concentration of a radioactive material, dose of radioactivity, and the possible scenario of spreading, could not operate due to insufficient information on the source of emission. In many cases, the actual external dose was quite low due to the shielding effect of the building. Iodine thyroid blocking immediately after the Fukushima accident was not officially measured in Japan and should be further 
investigated, although the dose of thyroid exposure by inhalation seemed to be quite low in individuals who were evacuated from the radius of the $20 \mathrm{~km}$ zone.

The WHO released its estimation of the doses received by the populations around Fukushima in May 2012 (WHO 2012). By applying incomplete SPEEDI's data at first and then using the airborne monitoring survey data by the Ministry of Education, Culture, Sports, Science and Technology of Japan (MEXT), based on conservative and theoretical assumptions, not taking onto account refuge and sheltering during 4 mo after the accident in the prepared evacuation area of the NPP or the measures that were implemented to limit the consumption of the food or restrictions on shipment. The WHO dose estimates were calculated from the viewpoint of protection and purposely used assumptions that overestimated true values (WHO 2012). According to this, a 1 y old child's thyroid equivalent dose was estimated to be in the range of $10-$ $100 \mathrm{mSv}$ in Minami-soma, Iwaki, and also Iitate-mura, and 1-10 mSv in Prefectures adjacent to Fukushima. However, these thyroid equivalent doses are markedly different from the actual values derived from the thyroidal screening and examination with a whole-body counter mentioned above.

According to the report on the thyroid internal exposure examination, which the Japanese Nuclear Safety Commission conducted from 26 March to 30 March just after the NPP disaster, a thyroid equivalent dose of $100 \mathrm{mSv}$ was considered to be an overestimate (Nagataki 2012). From this result, there would hardly be any increase in thyroid cancer out of the caution area, but according to the report by Hirosaki University (Tokonami et al. 2012), the thyroid equivalent dose might have reached several tens of millisieverts in the infants who stayed within a distance of $20 \mathrm{~km}$ from the reactor site at the time of the accident and it is necessary to observe them for a long period of time without a doubt.

Furthermore, on a basis of theoretical assumption of the preliminary dose estimation, the WHO has recently reported the health risk assessment results in Fukushima (WHO 2013). Those estimates using inappropriate retrospective dose assumption are far above reality may mislead the public into thinking there is more serious radiation health risk than actually exists. Unfortunately, the public concern on fear of childhood thyroid cancer risk from the Fukushima accident has never disappeared. From now on, it is 
necessary to develop a consensus of the accurate dose estimation based on the actual condition together with a continuation of regular thyroid ultrasound examination in Fukushima.

\section{OUTLINE OF FUKUSHIMA HEALTH MANAGEMENT SURVEY}

Fukushima Prefecture's residents are unavoidably exposed to radiation from the Fukushima NPP accident. Thus, the Fukushima Mimamori Project (Health Management Survey) was initiated in May 2011 for treating and managing residents' long-term health. This project is being carried out by Fukushima Medical University (FMU), as requested by the Prefecture, with the support of national funding. Started from scratch, the earnest efforts of those involved were realized by the establishment of the Radiation Medical Science Center for the Fukushima Health Management Survey on 1 September 2011.

At present, a basic study and four detailed studies are being conducted (Fig. 5). However, operations were started by a small number of full-time faculty members with limited ability to respond both within and outside the Prefecture, and hence there is an inevitable lag in the progress of the project. The busiest periods include daily inquiries exceeding 300 cases, with an onslaught of grievances occurring during the survey's early days. More than 150 dedicated prefectural and university workers, including those dispatched from other Prefectures, staff the center and its contact hotline every day. These are now composed with nine departments and one secretary section (Fig. 6). We can only bow our heads respectfully in gratitude for their struggles and daily hard work. In addition, the Fukushima Health Management Survey Review Committee has thus far met 10 times in the past $2 \mathrm{y}$ and is overcoming a myriad of obstacles. FMU is now under academic cooperation with various domestic and international research organizations to strengthen its role in radiation medical science research and education. 


\section{BASIC SURVEY TO ESTIMATE INDIVIDUAL RADIATION DOSE RATES}

Questionnaires are being mailed to all Prefecture residents as part of the basic survey. The questionnaires primarily inquire into each person's habits, conduct, and whereabouts when the airborne radioactivity was as its peak (during the 4 mo period after the earthquake). The aim is to estimate each person's external radiation dose that will respond to the questionnaire in Fukushima. Through a careful examination of these records and the data for airborne radiation levels, estimates will be made of cumulative radiation (millisievert/4 mo), using software developed by the National Institute of

\section{Radiological Sciences (Fig. 7).}

Out of the 2.02 million people to whom the questionnaire was mailed, $\sim 477,000$ have responded to the survey (23\%) as of 31 January 2013. The first results for 16,473 people were released for prioritized areas (Iitate-mura, the Yamakiya district of Kawamata, and Namie-machi where are designated as a prepared evacuated area) that were believed to receive relatively high external doses over the period of 4 mo following the accident (Fig. 8). Among those who were not directly working on projects close to or involved with radiation and the NPPs, $99.3 \%$ had $<10 \mathrm{mSv}$ of radiation exposure; the highest exposure of $25 \mathrm{mSv}$ was measured in only one person. The average was $<1 \mathrm{mSv} / 4 \mathrm{mo}$. The review committee assessed this data as an indication that "the impacts of radiation on health are minimal." However, future efforts are required for the health management of these individuals and to reduce their total radiation dose. The most recent data have also demonstrated that in the entire region of Fukushima, 99.8\% among 386,572 people were $<5 \mathrm{mSv} / 4$ mo as summarized in Fig 9. In detail, on a basis of geographical distribution, $>90 \%$ of the local residents in the middle and the northern regions of Fukushima have $<2 \mathrm{mSv} / 4 \mathrm{mo}, \sim 91 \%<1 \mathrm{mSv} / 4$ mo in the southern region of Fukushima, and $>99 \%<1 \mathrm{mSv} / 4$ mo in the Aizu and South Aizu regions.

Besides the first 4 mo external radiation exposure dose estimation in Fukushima, the data obtained from individual dose measurement using glass badges and by whole-body counter have been accumulated (Nagataki 2012), indicating no alarming evidence of radiation-induced health consequences. 


\section{FOUR DETAILED SURVEYS}

The four detailed surveys being conducted are: (1) thyroid ultrasound examination, (2) comprehensive medical checkup, (3) mental health and lifestyle surveys, and (4) survey on pregnant women and nursing mothers (FMU 2013).

\section{Thyroid ultrasound examination}

Although health effects directly due to radiation exposure are highly unlikely under the current circumstances and radiation levels in Fukushima, an increase in childhood thyroid cancer was seen in Chernobyl from the internal exposure to radioactive iodine. Because of the strong requirement by people in Fukushima as well as the central and local governments, we have started the most sophisticated thyroid ultrasound examinations since October 2011, targeting the children who were $<18$ y old at the time of the accident, around 360,000 for every $2 \mathrm{y}$ as long as the children are $<20 \mathrm{y}$ old and then every $5 \mathrm{y}$ when their age is $>20$ y old. These examinations will be repeated for a long time and will follow a standardized protocol developed by the FMU in cooperation with related hospitals and organizations. The protocol of thyroid ultrasound examination is well established so that highly sophisticated diagnostic approach is implemented with standardized data collection (Fig. 10).

As of March 2012, within $1 \mathrm{y}$ after the accident, $~ 38,000$ people from the evacuation zones $(80 \%$ population) have received examinations and the data were analyzed. Results showed that the majority did not have issues, although some did exhibit slight lumps (nodular lesions) or cysts. Approximately $0.5 \%$ of these individuals required detailed follow-up examinations (precision ultrasound, blood tests, urine analysis, and biopsies where appropriate). Among them, three cases of childhood thyroid cancer were diagnosed and operated successfully and seven more cases have been suspected as malignancy by fine needle aspiration biopsy examination. It needs to be noted that the sophisticated screening activities for thyroid disease that are under way in the Fukushima region will also lead to an increase in the incidence of thyroid cancer due to earlier detection of nonsymptomatic cases. It will therefore not be possible to 
compare the future observed thyroid cancer incidence with the figures of any previous report, as the baseline changes due to the screening activities. In this respect, it is necessary to establish a system for a long-term follow-up for all the children in Fukushima in careful comparison with the control areas. The overall results on 133,089 children have been reported (Table 1) and the examinations that will be carried out in the next several years are extremely vital for laying the foundation for long-term health management. After completion of these preliminary (first round) examinations for clarification of basal prevalence of thyroid diseases within $3 \mathrm{y}$, the full-scale thyroid examinations (second round) will then start in April 2014, hopefully targeting an established cohort population of 360,000 children from the entire Fukushima Prefecture at the time of the accident.

\section{Health checkup}

Detailed health examinations are being performed on the residents of evacuation zones and also on those deemed to be in need of health care based on their responses to the basic survey. The target population is around 210,000 including children who resided in the evacuated zones at the time of accident. The main objectives are to assess the examinees' health conditions and achieve early diagnoses and treatment of lifestyle and/or illnesses. The content of the examinations differs depending on the examinee's age, although all tests included in "Specified Medical Checkups" are typically conducted. For persons aged 16 y or older, the Special Health Checkup as a part of the Municipal National Health Insurance system, has been performed with additional items for comprehensive health check among adults aged 40 y or older in Hirono-machi, Naraha-machi, Tomioka-machi, Kawauchi-mura, Okuma-machi, Futaba-machi, Namie-machi, Kazurao-mura, and Iitate-mura (Fig.11). Also, visiting mass health check has been held for a total of 104 times at 29 locations since January 2012 for people aged 16 y or older who do not participate in the Special Health Checkup. For children aged 15 y or younger, health check has been held since January 2012 at 102 pediatric medical institutions in the Prefecture. Comprehensive health checks have been performed outside the Prefecture, with the cooperation of the Japan Anti-Tuberculosis Association. 
In summary, the 2011 Comprehensive Health Check from around 70,000 examinations clarified the general health conditions of evacuees from the government-designated evacuation zone after the Great East Japan Disaster. Obesity and hyperlipidemia exist even at young ages and increase in comparison with the previous years' data obtained from Fukushima Prefecture-in both male and female adults. Liver dysfunction and hyperuricemia increase at relatively young ages in male. Furthermore, hypertension, glucose dysmetabolism, and renal dysfunction increase in adulthood and are most common at older ages. We compared the comprehensive health check results after the disaster with the results of health examinations performed before the disaster in children and adults. The results suggested that the rates of obesity, glucose metabolic dysfunction, hyperlipidemia, and liver dysfunction after the disaster were high compared with those before the disaster. Regarding the factors that contributed to these results, changes of lifestyle, diet, exercise, and other personal habits caused by forced evacuation are suggested, although there were interfering factors such as the difference of health check period, age distribution, region distribution, and participation rate. Based on the results of the health check carried out in 2011, we are continuing the comprehensive health check long term and maintaining the system to prevent various diseases, including those life style related, of participants.

\section{Mental health and lifestyle surveys}

Changes in mental and physical health were indicated as the long-term effects of the Chernobyl nuclear reactor accident. Since psychological stress is conceivable in residents coping with life in evacuee shelters and anxiety toward the radiation, surveys are being administered to enable the provision of appropriate care. Residents in evacuation zones and individuals ( 210,000 people) deemed in need of health care based on basic survey results are asked to respond to questions about their current physical and mental condition, lifestyle (diet, sleeping habits, tobacco use, alcohol use, and exercise), how they have spent the past half year, and their experience of the Great East Japan Earthquake. Among them, around 92,000 people responded to the specific questionnaire that included the Strengths and Difficulties Questionnaire, Kessler's 6, and Post-Traumatic Stress Disorder Check List scoring issues. Individuals who 
need counseling and support are provided with telephone consultations by a clinical psychologist or other members of the Mental Health Support Team. If the support team member decides that specialized treatment is required, a physician from the FMU Radiation Health Counseling Team responds and conducts examinations as necessary. Although the detailed analysis will be separately reported, there are two important findings. For children, the most remarkable issues are physical symptoms, influences at school performance, irritation, anxiety and depression, and sensitivity to earthquakes and radiation taken from the category of "Reactions Amongst Children Due to 3.11 Disaster." For adults, the most remarkable issues are sleep issues, physical problems, depression, fear of future, and agitation, discount of evacuation life, taken from the category of "Reaction to Self from the 3.11 Disaster." All these data are still acute phase reaction and so we need to follow them up for a long time to compare the difference between acute and chronic reactions and also to clarify the quality of psycho-social and mental changes in order to support the recovery of physical and mental health conditions. Indeed, there are 3,351 among 73,569 population analyzed so far who need a care or support for their life-styled related issues such as sleep disturbance, chronic alcoholism, and smoking.

Although studies of populations exposed to low doses are limited in their ability to account for important lifestyle factors, such as cigarette smoking and medical x-ray exposures, our investigation should be and are being considered for reassurance and health care reasons. The mental care in Fukushima is, therefore, essentially needed for a long time as recommended by several experts similar to Chernobyl (Bromet et al. 2011; Boice 2012).

\section{Survey of expectant and nursing mothers}

A survey was administered to women who received their Maternal and Child Health Handbooks within and outside the Prefecture, and to those who underwent pregnancy checkups or gave birth after 11 March 2011. They were asked to respond to questions including the health and pregnancy checkups they received since the earthquake, their physical condition during their pregnancy, the birth of their child, and their mental well being. A total of 15,954 questionnaires were distributed in January 2011 and 9,266 
responses were returned by 31 August 2012 (response rate 58.1\%). Telephone counseling was provided by midwives and public health nurses for 1,393 respondents of 9,228 (counseling rate 15.1\%), who had been identified as respondents requiring support on the basis of the survey response $(1,213$ indicated signs of depression and 180 requested support on their own will). Along with protecting the long-term health of expectant and nursing mothers, these efforts are intended to provide peace of mind to those planning childbirth in Fukushima Prefecture and help improve perinatal care in the Prefecture.

At the center, maternity and public health nurses are always on duty, handling calls and e-mails related to childcare and child rearing. For consultees who require further support, FMU maternity nurses and hospital nurses are available by telephone. In certain cases, the patient's existing obstetrician or an FMU professor may offer support. According to the local reports, there are neither any increase of miscarriage nor artificial abortion owing to the extensive efforts of the Japanese Medical Association, especially obstetricians and gynecologists. Furthermore by the Japan Association of Obstetricians and Gynecologists (JAOG), the congenital malformations were evaluated in babies delivered in Fukushima Prefecture. There is no obvious increased prevalence rate of congenital malformations at the present time compared with the rate of birth defects monitoring of JAOG. However, it is necessary to gather more cases to draw a conclusion.

\section{REGULAR HEALTH CHECKUPS TO SUPPORT RECOVERY EFFORTS}

The surveys are intended as a specific response to initial radiation exposure and to mental traumas caused by the accident and evacuation. The standardization and close monitoring of diagnostic examinations outside of these surveys remain a pending issue in the context of long-term health management efforts. In particular, it is important not only for patients but for the public to understand that due to the latent period for cancer induction. If an ultrasound thyroid examination shows signs of cancer in $<4$ y after the accident, there is no tenable argument that could link that cancer to radiation exposure from

the accident. Going forward, we need to address the issue of latency periods regarding examination results 
and the development of cancer from the standpoint of cancer biology. Also, we need to devise a regional cancer registry for patients. Birth, illness, old age, and death are inevitable, and a risk-free society is not completely achievable. Although much has been lost, some things have been gained as a result of this recent tragedy. Fortunately, there have been no deaths from radiation exposure due to the nuclear accident. It seems that being grateful for having life (being allowed to live) and facing difficulties alongside our companions contribute to further hope and courage.

\section{RESPONSIBILITY OF MEDICAL AND HEALTH PROFESSIONALS}

In the view of severity, even though it is a rare accident, Japan, which previously aimed to become a nuclear power-based nation still aims to the scientific and technological-oriented nation, and to be familiar with the medical knowledge about and techniques for handling nuclear and radiological accidents. Now we are facing more difficult parts of a recovery and reconstruction with the existing exposure condition not only in Fukushima but surrounding prefectures, which may now have radiation levels similar to natural high background areas in the world.

First there needs to be have a common understanding about the role and responsibility of health care workers in any emergency and reconstruction process utilizing similar considerations as those used for disaster prevention. As we know, what is done cannot be undone, it is necessary for officials and others to understand the difference between the concept of radiation protection in ordinary time and radiation protection during emergencies as well as the importance of involving the stakeholders in each community.

The world has been enlightened not only by the information of the nuclear accident itself but also by efforts of medical exposure reduction and mitigation. In the case of routine medical exposure, there is no recommended dose limit is not set, but justification includes the judgment of the physician; the diagnosis and radiological treatment for the patient is based on the conceptual agreement that the benefits are much greater than the radiation risk. Of course, the effort to reduce and to avoid exposure in any circumstances is required but a concept of justification is the most important key word on medical exposure for any 
facilitators: physicians and radiologists. On the other hand, use of artificial radioactive material is done using principles and measures to prevent exposure in other areas, such as the prevention of the spread of contamination and protection of workers.

The large amount of radioactive material that was released from the Fukushima NPP accident into the environment has raised new issues regarding exposure of the general population. The residents in Fukushima were exposed unnecessary and useless environmental radioactive contamination especially by radioactive ${ }^{134} \mathrm{Cs}$ and ${ }^{137} \mathrm{Cs}$. It is important for the medical professionals to provide an appropriate response for the residents with the aims of recovery and reconstruction after the accident. Although lessons of the Chernobyl nuclear reactor accident need to be utilized in this correspondence, not only the health aspect but also the risk-and-benefit side in addition to the concept of dose limit and reference level, and furthermore, the evaluation from various perspectives, such as the psychosocial aspects, are necessary to understand the concept of optimization of exposure reduction measures. Since there are many complexities after the Fukushima NPP accident, we, the Japanese, need to be more aware of ICRP activities such as a necessity of consideration of the justification and optimization of protection strategies and the introduction and application of a reference level to drive the optimization process (ICRP 2009). The ICRP strongly emphasizes the effectiveness of directly involving stakeholders in the management of difficult conditions.

The above countermeasures should be learned by medical professionals themselves in order to communicate with the public. Moreover, any medical staff is expected to perform its social responsibility more widely during and after the nuclear and radiological accidents, especially under the most difficult phase to support the return back to the contaminated areas which would have annual dose less than several millisievert after the official restricting regulations have been withdrawn (Fig. 12). Any kind of support activities for ensuring security and safety is then needed for those who will decide in future to return back to their homeplace. 


\section{CONCLUSION}

The risk of radiation-associated physical health consequences for residents in Fukushima is quite different from that of Chernobyl and considerably low or undetectable at the standpoint of the estimated radiation dose exposed by the accident. However, there is a similarity of social, psychological, and economic impact between two serious NPP accidents. Therefore the current ongoing program of the Fukushima Health Management Survey is essentially important to support a long-term comprehensive health management and metal care for the residents in Fukushima and also the evacuated people from Fukushima.

As we support residents in their recovery and return to their homes, understanding each individual's state with respect to radiation and regularly monitoring their health conditions contribute to the region's rebirth and restoration (Taira et al. 2012). To that end, we plan to build and maintain a framework for residents to self-access information about their radiation dose rates and for the medical infrastructure to offer readily accessible health consultations and examinations. The challenges associated with the health care management of Fukushima Prefecture's residents are numerous, and it is only with the support of everyone that we will be able to move forward with these projects. We humbly request the kind consideration and cooperation of the prefecture's and country's healthcare professionals and also of the international societies.

The slogan of FMU is "Let's Change Our Tragedy to Miracle-Start Together from Fukushima with Health and Medical Science Research." Our goals include overcoming the complications of this nuclear disaster, changing and reforming our difficult and disordered psychosocial situation, and leading Fukushima in transforming in the future, as the "Number One Prefecture of Longevity in Japan."

\section{ACKNOWLEDGEMENTS}

The special honorable occasion of the Tenth Annual Warren K. Sinclair Keynote Address is devoted to all the victims in sorrow by the Great East Japan Earthquake. I really appreciate the Fukushima Health 
Management Survey Group at FMU and also Nagasaki University, especially Emeritus Professor Shigenobu Nagataki.

\section{CONFLICTS OF INTEREST}

The author declares no conflict of interest.

\section{REFERENCES}

Balonov M. The Chernobyl accident as a source of new radiological knowledge: implications for Fukushima rehabilitation and research programmes. J Radiol Prot 33:27-40; 2013.

Boice JD Jr. Radiation epidemiology: a perspective on Fukushima. J Radiol Prot 32:N33-40; 2012.

Brenner AV, Tronko MD, Hatch M, Bogdanova TI, Oliynik VA, Lubin JH Zablotska LB, Tereschenko VP, McConnell RJ, Zamotaeva GA, O’Kane P, Bouville AC, Chaykovskaya LV, Greenebaum E, Paster IP, Shpak VM, Ron E. I-131 dose response for incident thyroid cancers in Ukraine related to the Chernobyl accident. Environ Health Perspect 119: 933-939; 2011.

Bromet EJ, Havenaar JM, Guey LT. A 25 year retrospective review of the psychological consequences of the Chernobyl accident. Clin Oncol 23:297-305; 2011.

Cardis E, Kesminiene A, Ivanov V, Malakhova I, Shibata Y, Khrouch V, Drozdovitch V, Maceika E, Zvonova I, Vlassov O, Bouville A, Goulko G, Hoshi M, Abrosimov A, Anoshko J, Astakhova L, Chekin S, Demidchik E, Galanti R, Ito M, Korobova E, Lushnikov E, Maksioutov M, Masyakin V, Nerovnia A, Parshin V, Parshkov E, Piliptsevich N, Pinchera A, Polyakov S, Shabeka N, Suonio E, Tenet V, Tsyb A, Yamashita S, Williams D. Risk of thyroid cancer after exposure to ${ }^{131} \mathrm{I}$ in childhood. J Natl Cancer Inst 97:724-732; 2005.

Demidchik YE, Saenko VA, Yamashita S. Childhood thyroid cancer in Belarus, Russia, and Ukraine after Chernobyl and at present. Arq Bras Endocrinol Metabol 51:748-762; 2007.

FMU. Fukushima Radiation and Health. Radiation Medicine Science Center for the Fukushima Health 
Management Survey, Fukushima Medical University [online]. Available at: http://fukushimamimamori.jp/. Accessed 24 May 2013.

Gudmundsson J, Sulem P, Gudbjartsson DF, Jonasson JG, Masson G, He H, Jonasdottir A, Sigurdsson A, Stacey SN, Johannsdottir H, Helgadottir HT, Li W, Nagy R, Ringel MD, Kloos RT, de Visser MC, Plantinga TS, den Heijer M, Aguillo E, Panadero A, Prats E, Garcia-Castaño A, De Juan A, Rivera F, Walters GB, Bjarnason H, Tryggvadottir L, Eyjolfsson GI, Bjornsdottir US, Holm H, Olafsson I, Kristjansson K, Kristvinsson H, Magnusson OT, Thorleifsson G, Gulcher JR, Kong A, Kiemeney LA, Jonsson T, Hjartarson H, Mayordomo JI, Netea-Maier RT, de la Chapelle A, Hrafnkelsson J, Thorsteinsdottir U, Rafnar T, Stefansson K. Discovery of common variants associated with low TSH levels and thyroid cancer risk. Nat Genet 44:319-322; 2012.

Hayashida N, Sekitani Y, Kozlovsky A, Rafalsky R, Gutevich A, Daniliuk V, Yamashita S, Takamura N. Screening for ${ }^{137} \mathrm{Cs}$ body burden due to the Chernobyl accident in Korosten City, Zhitomir, Ukraine: 1996-2008. J Radiat Res 52: 629-633; 2011.

IAEA. Leukemia, solid cancers and circulatory diseases. In: The Chernobyl forum: 2003-2005. Second revised version. Vienna; 2006; 18-19.

ICRP. Application of the Commission's recommendations to the protection of people living in long-term contaminated areas after a nuclear accident or a radiation emergency. New York: Elsevier; ICRP Publication 111. Ann. ICRP 39(3); 2009.

Ivanov VK, Kashcheev VV, Chekin SYu, Maksioutov MA, Tumanov KA, Vlasov OK, Shchukina NV, Tsyb AF. Radiation-epidemiological studies of thyroid cancer incidence in Russia after the Chernobyl accident (estimation of radiation risks, 1991-2008 follow-up period). Radiat Prot Dosim 151:489$499 ; 2012$.

Jacob P, Bogdanova TI, Buglova E, Chepurniy M, Demidchik Y, Gavrilin Y, Kenigsberg J, Meckbach R, Schotola C, Shinkarev S, Tronko MD, Ulanovsky A, Vavilov S, Walsh L. Thyroid cancer risk in areas of Ukraine and Belarus affected by the Chernobyl accident. Radiat Res 165:1-8; 2006.

Kazakov VS, Demidchik EP, Astakhova LN. Thyroid cancer after Chernobyl. Nature 359:21; 1992. 
Likhtarev IA, Sobolev BG, Kairo IA, Tronko ND, Bogdanova TI, Oleinic VA, Epshtein EV, Beral V.

Thyroid cancer in the Ukraine. Nature 375:365; 1995.

MEXT. Monitoring information of environmental radioactivity level, MEXT; 2011 [online]. Available at: http://radioactivity.mext.go.jp/en/list/195/list-1.html. Accessed 24 May 2013.

Nagataki S. Thyroid consequences of the Fukushima Nuclear Reactor Accident. Eur Thyroid J 1:148-158; 2012.

Ron E. Ionizing Radiation and cancer risk: evidence from epidemiology. Pediatr Radiol 32:232-237; 2002.

Ron E, Lubin JH, Shore RE, Mabuchi K, Modan B, Pottern LM, Schneider AB, Tucker MA, Boice JD Jr. Thyroid cancer after exposure to external radiation: a pooled analysis of seven studies. 1995. Radiat Res 178:AV43-60; 2012.

Saenko V, Yamashita S. Chernobyl thyroid cancer 25 years after: in search of a molecular radiation signature. Hot Thyroidology. HT 8/10; 2010 [online]. Available at: http://www.hotthyroidology.com/print.php?ID=216. Accessed 24 May 2013.

Saenko V, Ivanov V, Tsyb A, Bogdanova T, Tronko M, Demidchik Y, Yamashita S. The Chernobyl accidents and its consequences. Clin Oncol 23:234-243; 2011.

Suzuki K, Yamashita S. Low-dose radiation exposure and carcinogenesis. Jpn J Clin Oncol 42:563-568; 2012.

Taira Y, Hayashida N, Yamaguchi H, Yamashita S, Endo Y, Takamura N. Evaluation of environmental contamination and estimated radiation doses for the return to residents' homes in Kawauchi Village, Fukushima Prefecture. PLoS One 7:e45816; 2012.

Takahashi M, Saenko VA, Rogounovitch TI, Kawaguchi T, Drozd VM, Takigawa-Imamura H, Akulevich NM, Ratanajaraya C, Mitsutake N, Takamura N, Danilova LI, Lushchik ML, Demidchik YE, Heath S, Yamada R, Lathrop M, Matsuda F, Yamashita S. The FOXE1 locus is a major genetic determinant for radiation-related thyroid carcinoma in Chernobyl. Hum Mol Genet 19:2516-2523; 2010.

Tokonami S, Hosoda M, Akiba S, Sorimachi A, Kashiwakura I, Balonov M. Thyroid doses for evacuees from the Fukushima nuclear accident. Sci Rep 2:507; 2012. 
Tronko M, Bogdanova T, Likhtarev I, Komisarenko I, Kovalenko A, Epshtein O, Tereshchenko V, Shpak V, Gulak L. Thyroid gland and radiation (fundamental and applied aspects): 20 years after the Chernobyl accident. In: Shibata Y, Namba H, Suzuki K, Tomonaga M, eds. Radiation risk perspectives. International Congress Series 1299. New York: Elsevier; 2007; 46-53.

UNSCEAR. Report to the general assembly with scientific annexes. Volume II. Annex D. Health effects due to radiation from the Chernobyl accident. New York: United Nations; 2011.

WHO. Health effects of the Chernobyl accident and special health care programmes. Report of the UN Chernobyl Forum Expert Group "Health". Bennet B, Repacholi M, Carr Zh, eds. Geneva: WHO Press; 2006.

WHO. Preliminary dose estimation from the nuclear accident after the 2011 Great East Japan Earthquake and Tsunami. WHO; 2012 [online]. Available at: http://www.who.int/ionizing_radiation/pub_meet/fukushima_dose_assessment/en/. Accessed 24 May 2013.

WHO. Health risk assessment from the nuclear accident after the 2011 Great East Japan earthquake and tsunami, based on a preliminary dose estimation. WHO; 2013 [online]. Available at: http://www.who.int/ionizing_radiation/pub_meet/fukushima_report/en/index.html. Accessed 24 May 2013.

Williams D. Twenty years' experience with post-Chernobyl thyroid cancer. Best Pract Res Clin Endocrinol Metab 22:1061-1073; 2008.

Yamashita S. Comments on thyroid-related studies by the Chernobyl Sasakawa Health and Medical Cooperation Project. In: Yamashita S, Shibata Y, eds. Chernobyl: a decade. Excerpta Medica, International Congress Series 1156. New York: Elsevier; 1997: 95-100.

Yamashita S, Saenko V. Mechanisms of disease: molecular genetics of childhood thyroid cancers. Nature Clin Pract Endocrionol Metab 3:422-429; 2007.

Yamashita S, Carr Z, Repacholi M. Long-term health implications of the Chernobyl accident and relevant projects of the World Health Organization. Health Phys 93: 538-541; 2007. 
Zablotska LB, Ron E, Rozhko AV, Hatch M, Polyanskaya ON, Brenner AV, Lubin J, Romanov GM, McConnell RJ, O’Kane P, Evseenko VV, Drozdvitch VV, Luckyanov N, Minenko VF, Bouville A, Masyakin VB. Thyroid cancer risk in Belarus among children and adolescents exposed to radioiodine after the Chernobyl accident. Br J Cancer 104:181-187; 2011. 


\section{FIGURE LEGENDS}

Fig. 1. Dose-response relationship for developing thyroid cancer after external or internal radiation exposure. Radiation exposure of the thyroid at young age is the most clearly defined environmental factor associated with risk for thyroid cancer. Risk estimates for external and internal exposures are generally comparable. Graphs are derived from references Ron (2002) and Ivanov et al. (2012), respectively.

Fig. 2. Incidence of thyroid cancer in residents of radiocontaminated territories around Chernobyl. Data for Belarus is derived from Demidchik et al. (2007), for Ukraine from Tronko et al. (2007) and relate to the whole countries. Data for four radiocontaminated regions of Russia (Bryansk, Kaluga, Orel, and Tula Oblasts) were kindly provided by V.K. Ivanov (National Radiation and Epidemiological Registry, Medical Radiological Research Center, Russia).

Fig. 3. Evolution of mutational events and clinicopathological features of papillary thyroid carcinoma in time after the Chernobyl nuclear reactor accident inferred from Williams (2008).

Fig. 4. Monitoring information of environmental radioactivity level at nine monitoring points in Fukushima Prefecture from 11 March to 26 March 2011. Data is derived from MEXT (2011); the graph originally appeared in previous work (Nagataki 2012).

Fig. 5. Outline of the Fukushima Health Management Survey.

Fig. 6. Organization of the Fukushima Health Management Survey.

Fig. 7. Estimation of individual radiation doses and associated health risk by the National Institute of Radiological Sciences. 
Fig. 8. Distribution of estimated cumulative effective dose (millisievert) due to external exposure from 11 March to 11 July 2011 in prioritized areas including Kawamata, Namie, and Iidate districts of the Deliberate Evacuation Area.

Fig. 9. Distribution of estimated cumulative effective dose (millisievert) due to external exposure from 11 March to 11 July 2011 in the residents of entire Fukushima Prefecture according to data of 13 February 2013.

Fig. 10. Flow chart of thyroid ultrasound examination in Fukushima Prefecture.

Fig. 11. Map of an administrative district in Fukushima Prefecture.

Fig. 12. Results of the airborne monitoring survey by MEXT as of 1 February 2012 showing surface contamination maps for ${ }^{134} \mathrm{Cs}$ and ${ }^{137} \mathrm{Cs}$ in the eastern part of Fukushima Prefecture. "Deliberate Evacuation Area" and "Restricted Area" have been established in 22 April 2011. 
Table 1. Results of the detailed thyroid survey by ultrasound screening as of January 2013.

\begin{tabular}{|c|c|c|c|}
\hline Judgment & Interpretation & Number & $\%$ \\
\hline A subtotal & Within normal range & 132,354 & $99.5 \%$ \\
\hline (A1) & No specific finding & 77,497 & $58.3 \%$ \\
\hline \multirow[t]{2}{*}{$\begin{array}{l}\mathrm{A} \\
(\mathrm{A} 2)\end{array}$} & $\begin{array}{l}\text { Nodule with } \leq 5.0 \mathrm{~mm} \text { or/and } \\
\text { Cyst with } \leq 20.1 \mathrm{~mm}\end{array}$ & 54,857 & $41.2 \%$ \\
\hline & Nodule with $\geq 5 \mathrm{~mm}$ or/and & & \\
\hline \multirow[t]{2}{*}{ B } & Cyst with $\geq 20.1 \mathrm{~mm}$ & 734 & $0.5 \%$ \\
\hline & Recommended second screening & & \\
\hline $\mathrm{C}$ & Needed further examination & 1 & $0.001 \%$ \\
\hline Total & & 133,089 & $100 \%$ \\
\hline
\end{tabular}




\section{External exposure}

\section{ERR/Gy 7.7 [1.1 - 32]}

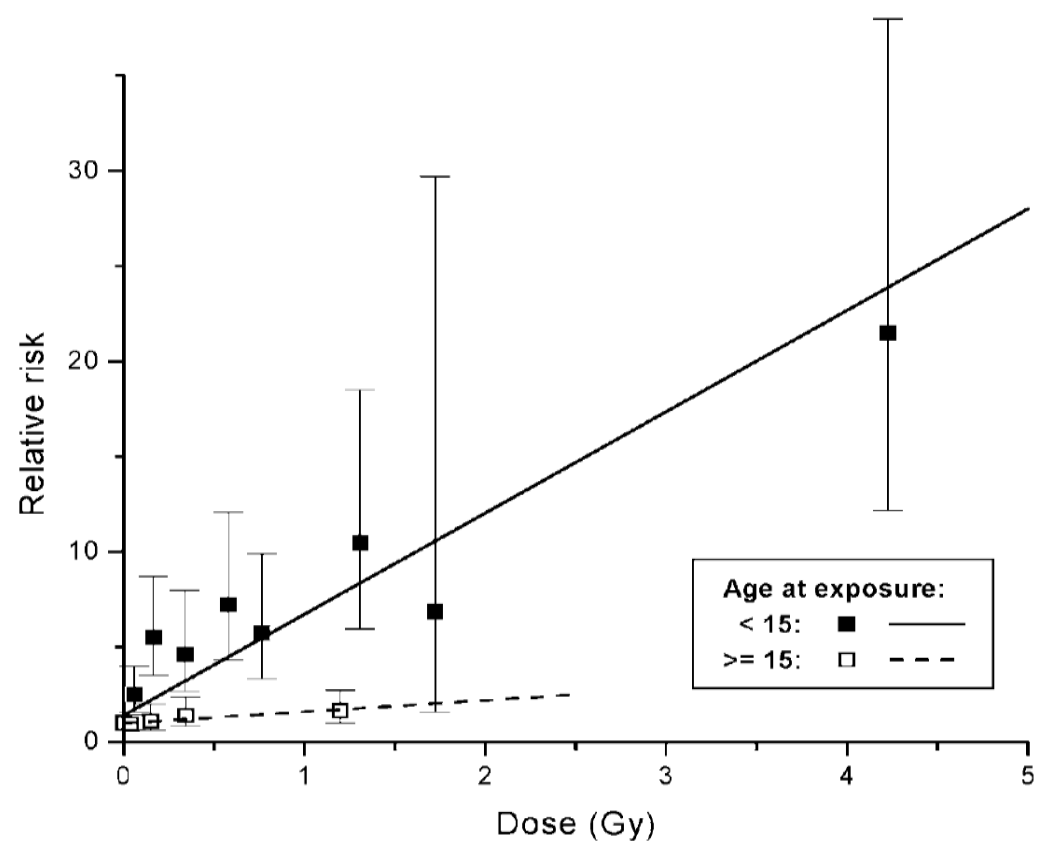

Internal exposure, Chernobyl (0-17 y.o.)

OR at $1 \mathrm{~Gy} \sim 5.5-8.4$ [ERR/Gy $1.9-19$ ]

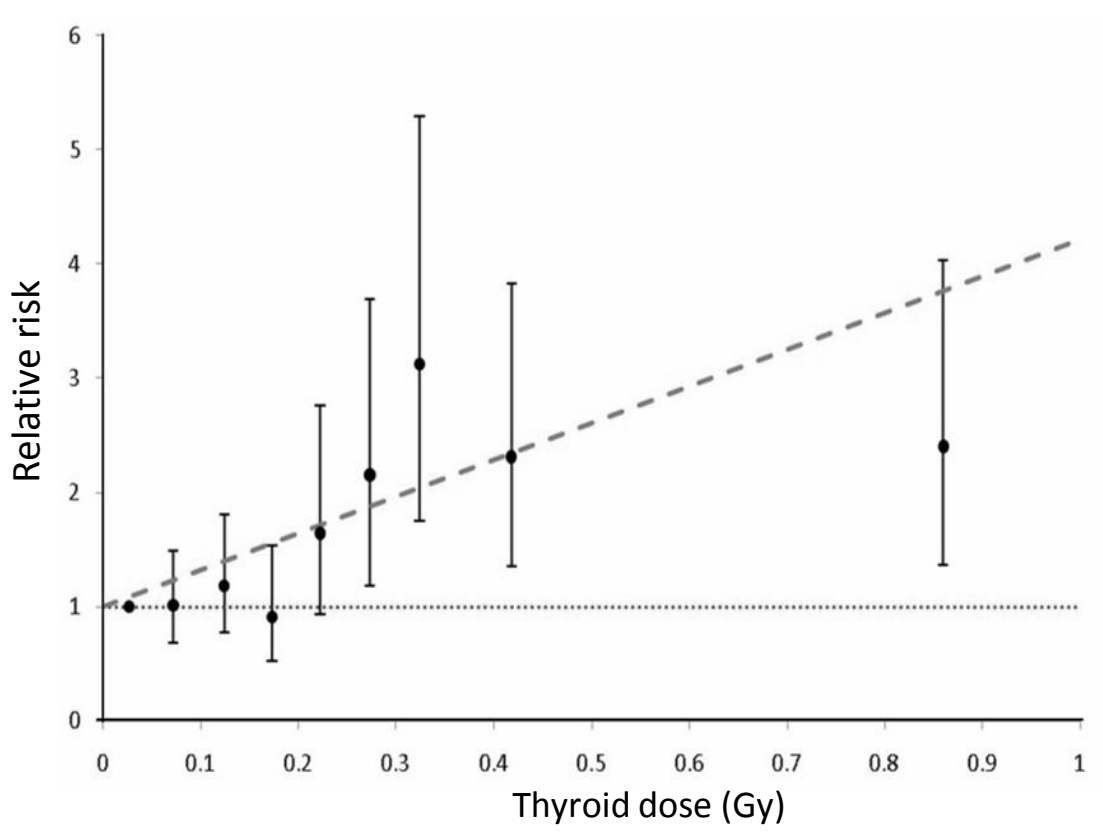

Fig. 1 
Belarus
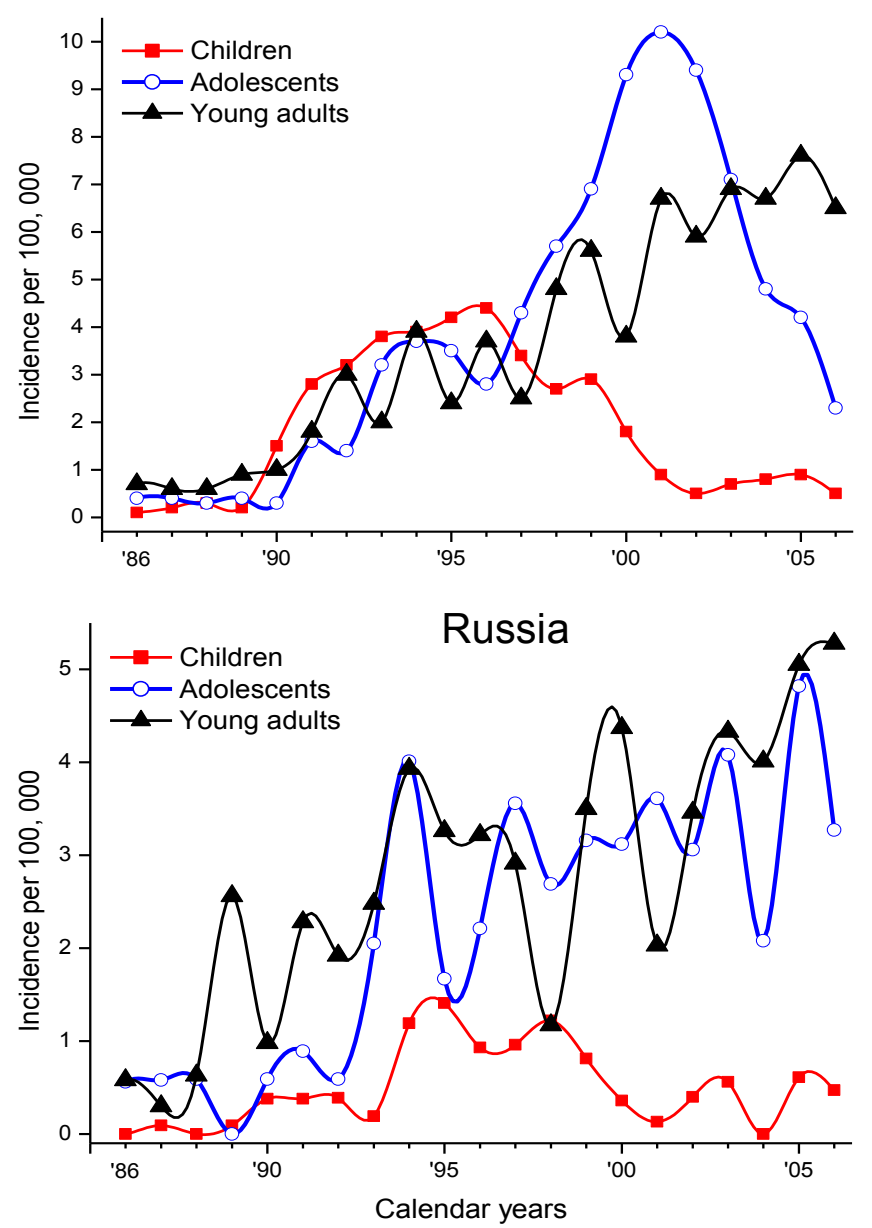

Ukraine
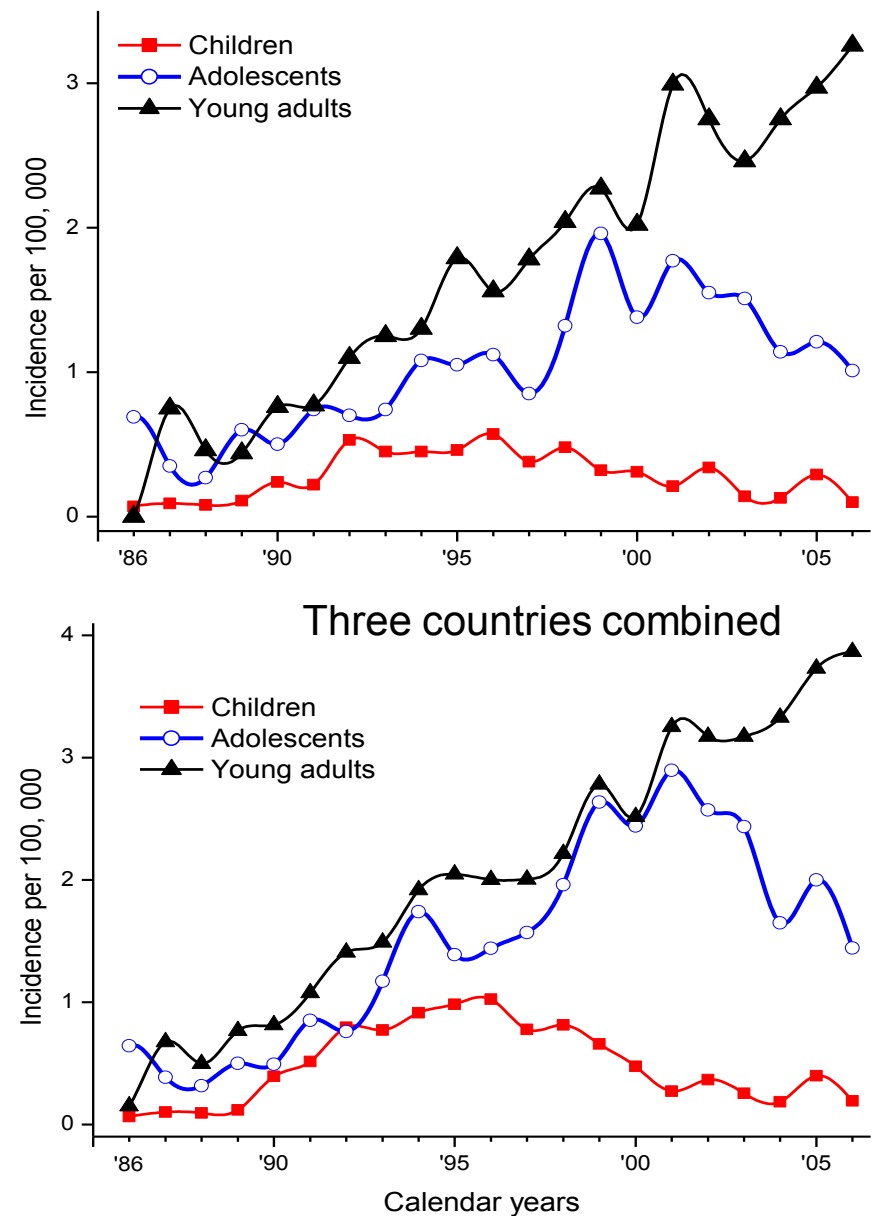

Fig. 2 


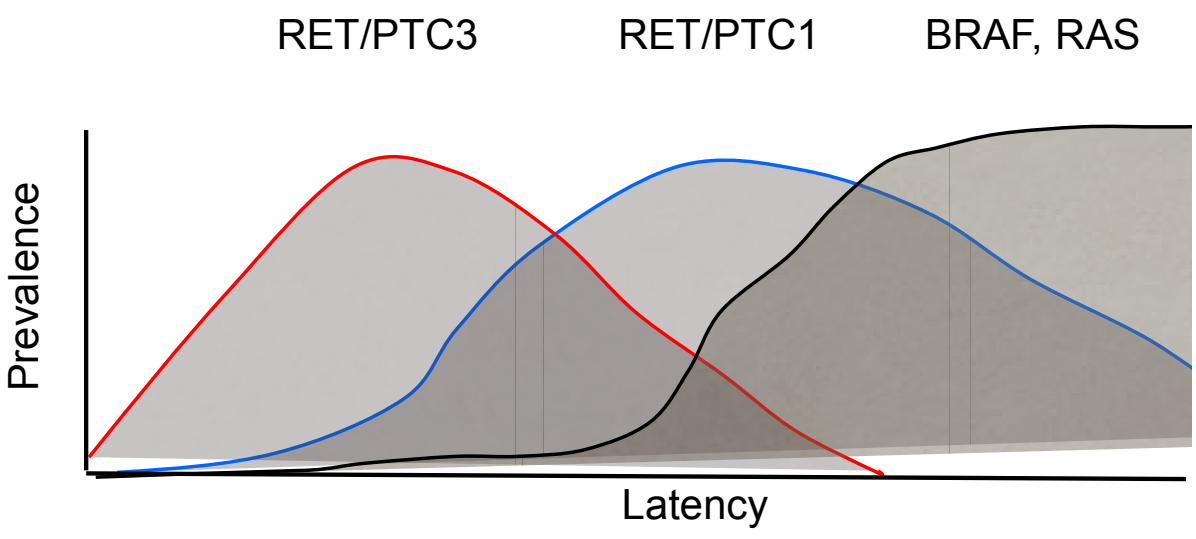

\begin{tabular}{llll}
\hline Morphology & Sol, Sol-Fol & Classic & Classic, Encaps \\
Clinical course & Aggressive $\uparrow$ & Typical & Aggressive $\downarrow$ \\
\hline Latency, years & $4-10$ & $7-17$ & $15-\ldots$ \\
\hline
\end{tabular}

Fig. 3 


\section{( $\mu \mathrm{Sv} / \mathrm{h})$}

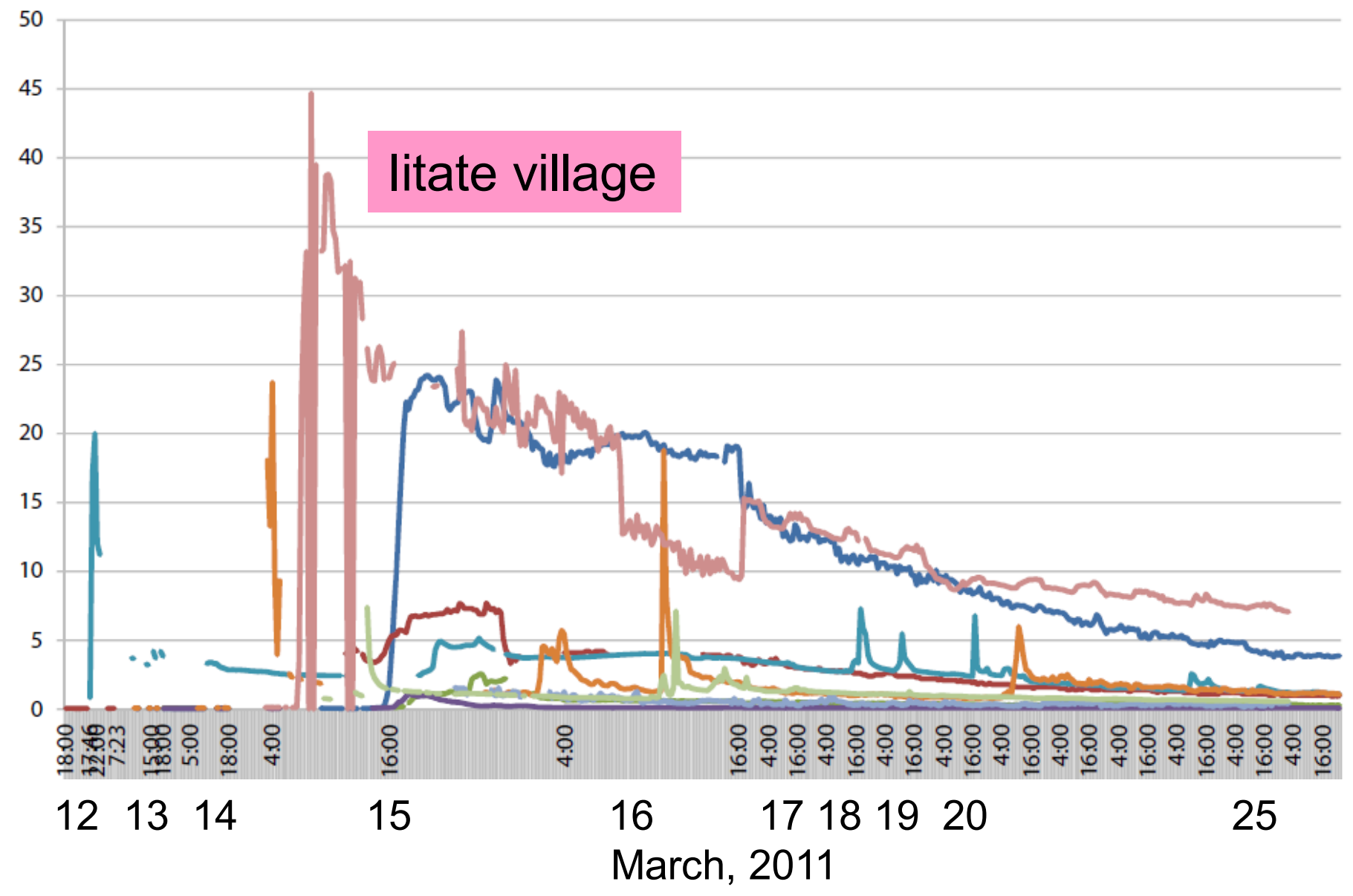

- Fukushima City

— Shirakawa City

- Aizu City

— Minamiaizu City

_ Minamisouma City

Iwaki City

_ Tamamura Village

Iitate Village

Iwaki City

Fig. 4 


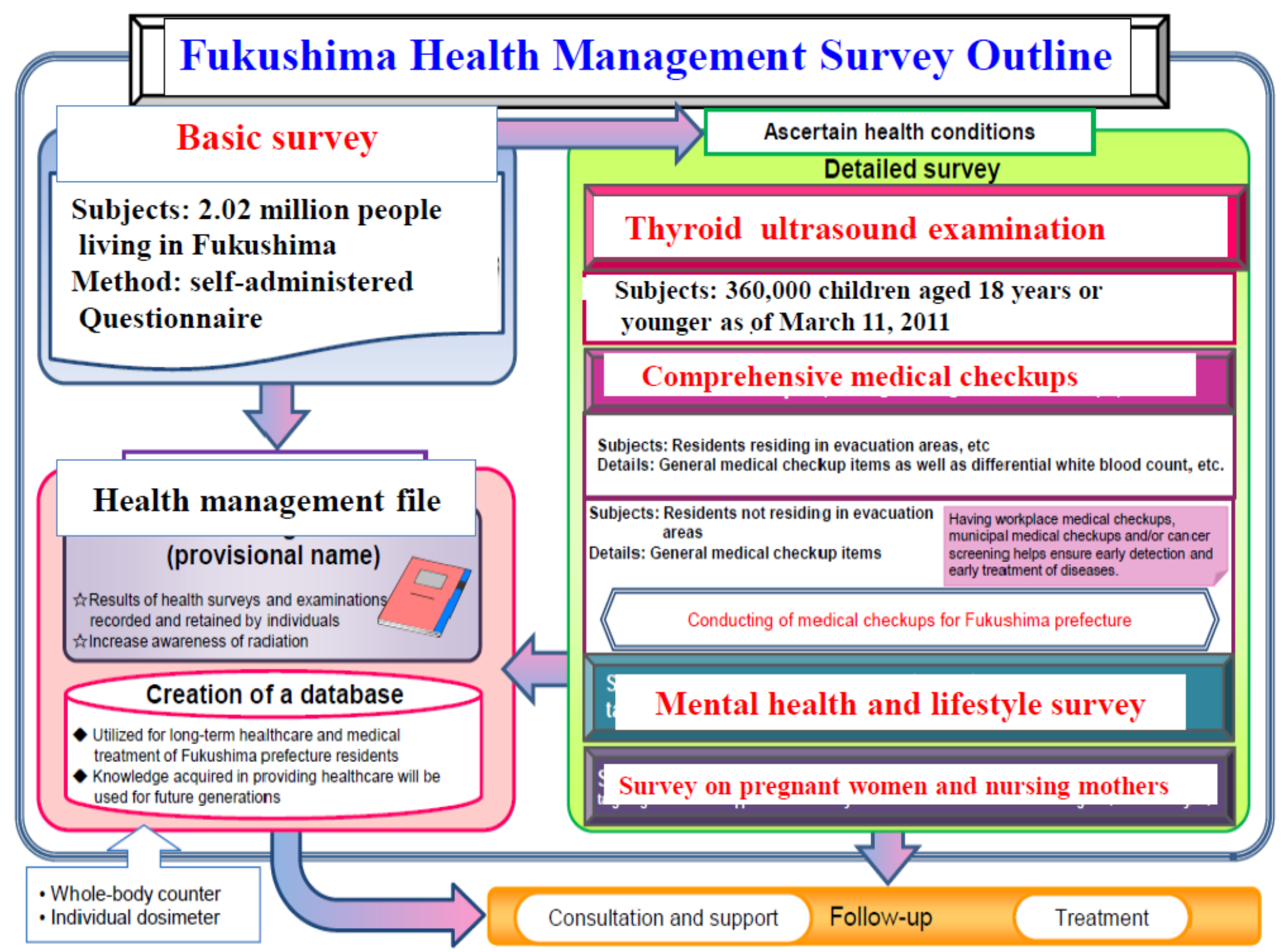

Fig. 5 


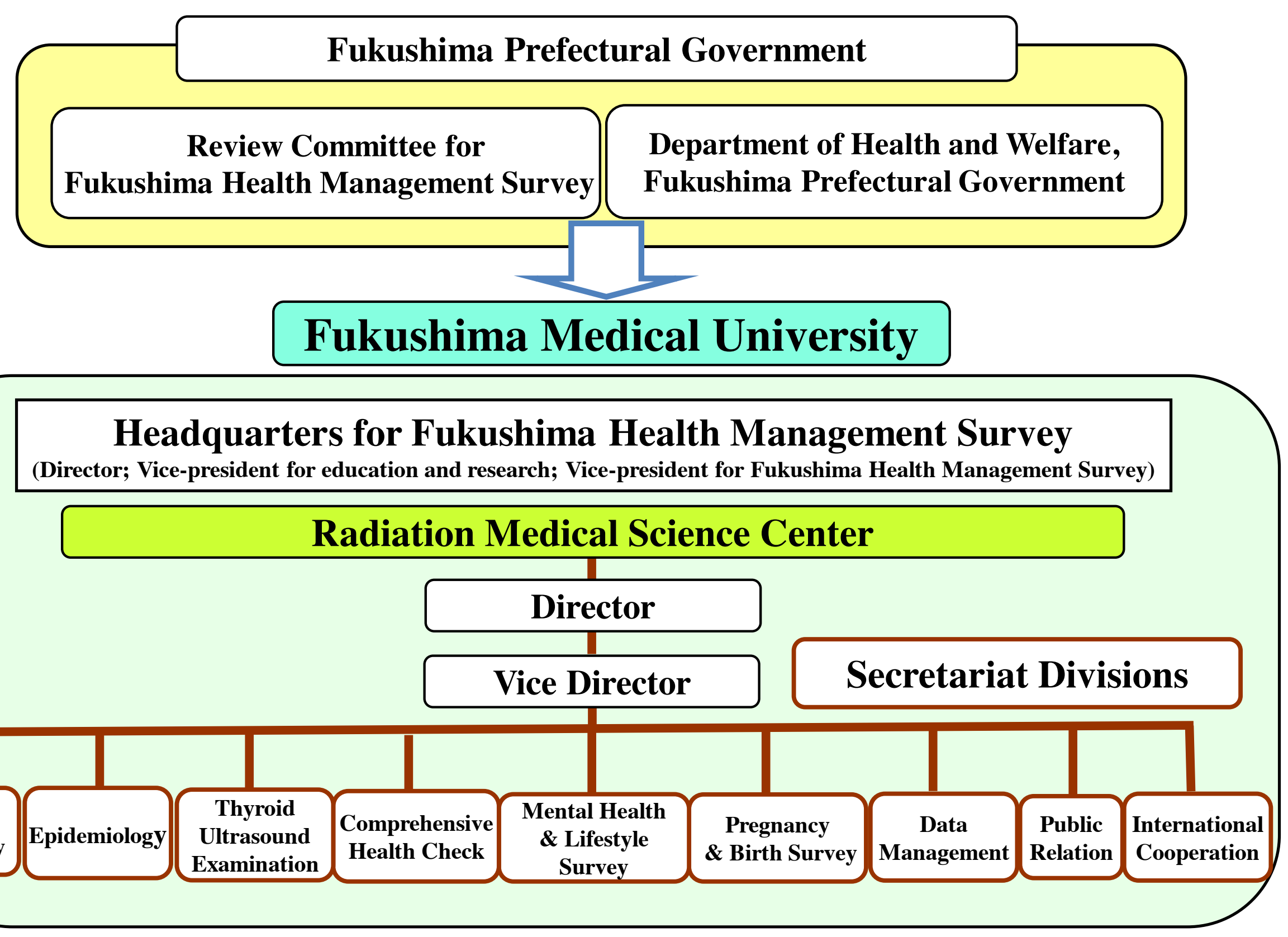

Fig. 6 


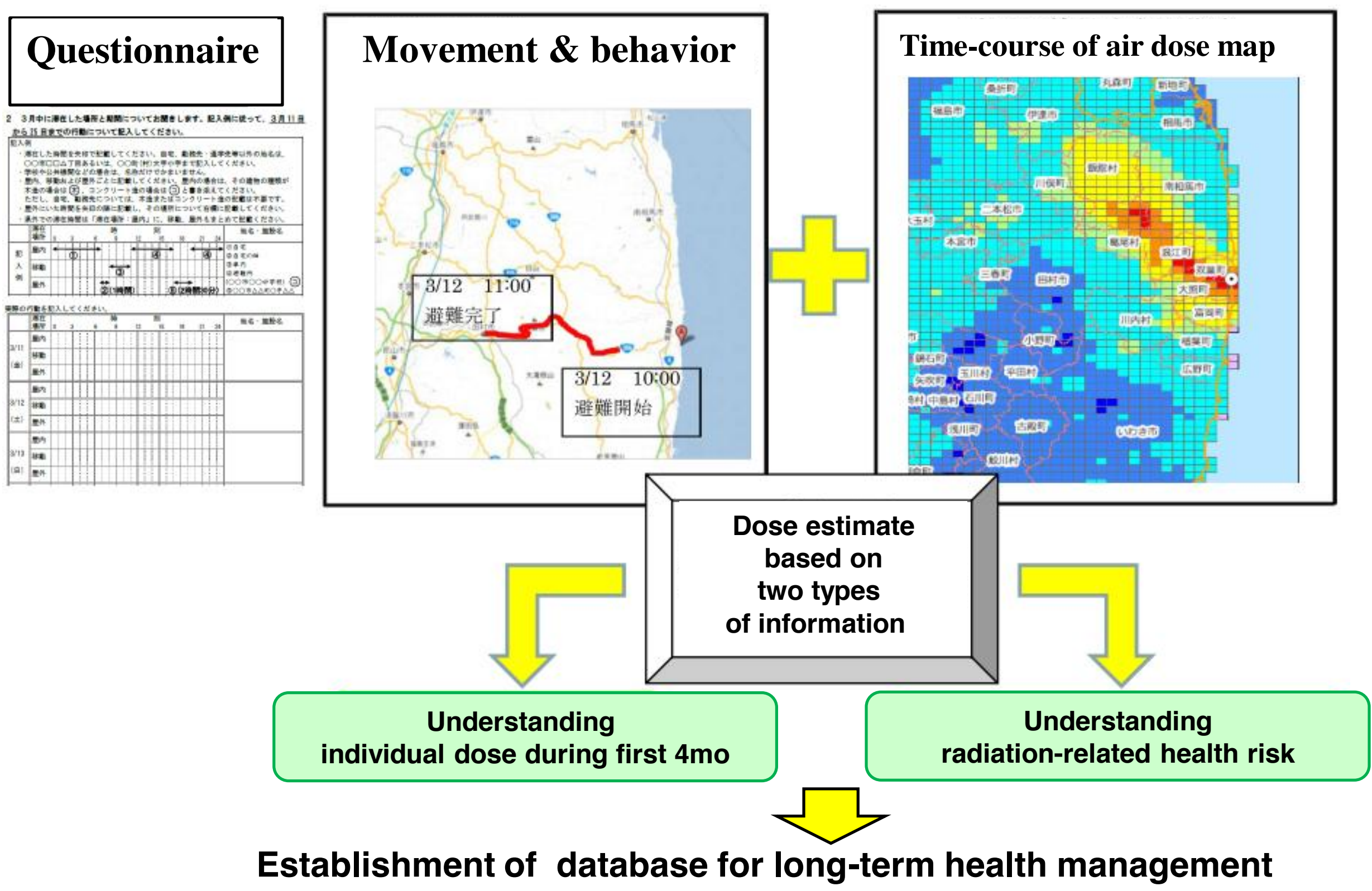

Fig. 7 


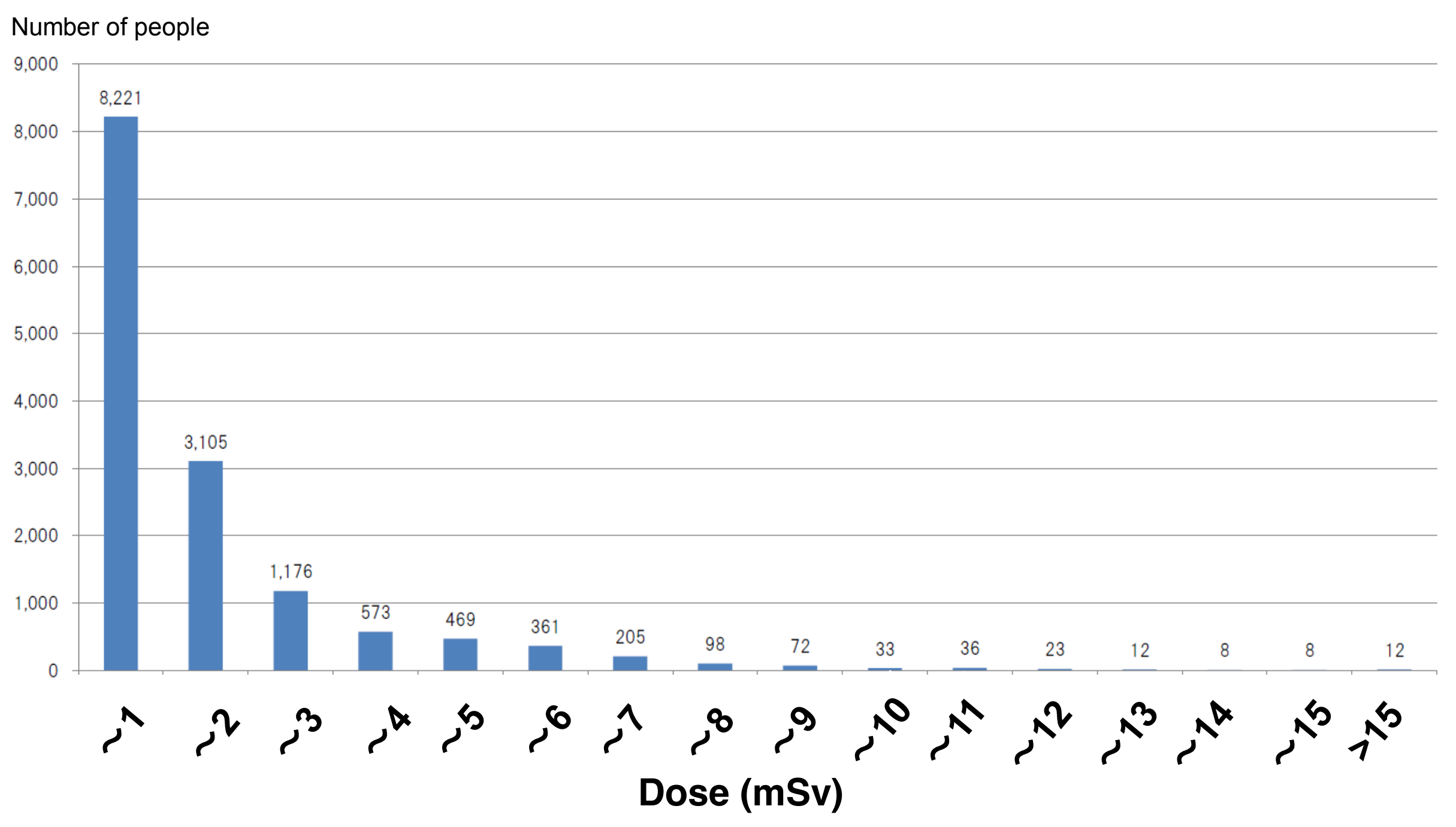

Fig. 8 
Number of people

300,000

256,281

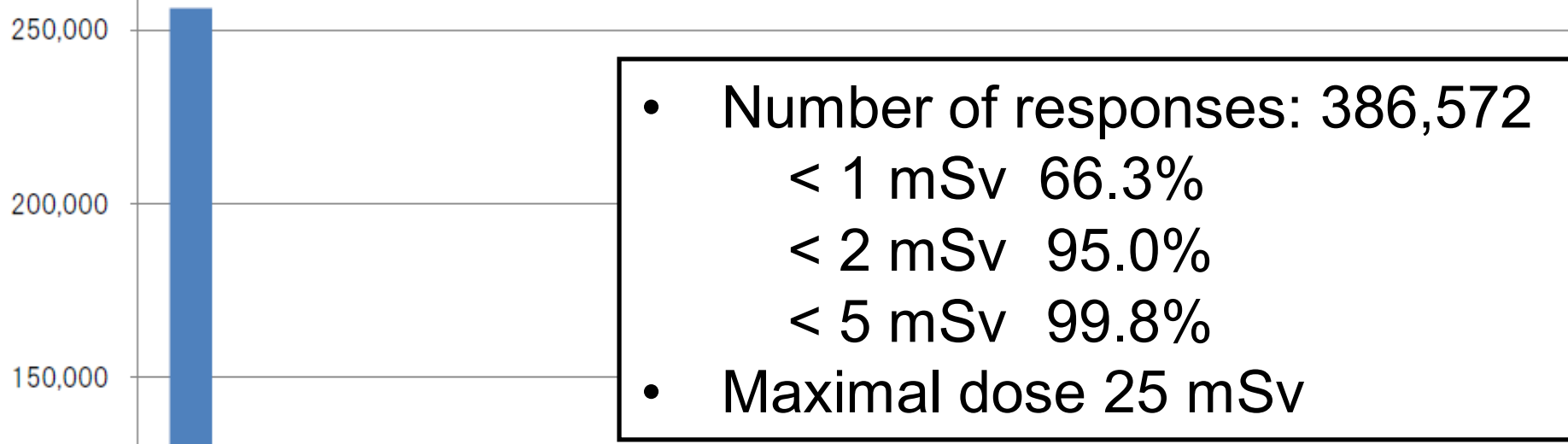

110,894

100,000

.

16,726

0

$\hat{\imath}, r^{2} \hat{r}^{\infty}$

Dose (mSv)

Fig. 9 


\section{First Screening (Portable US machine)}

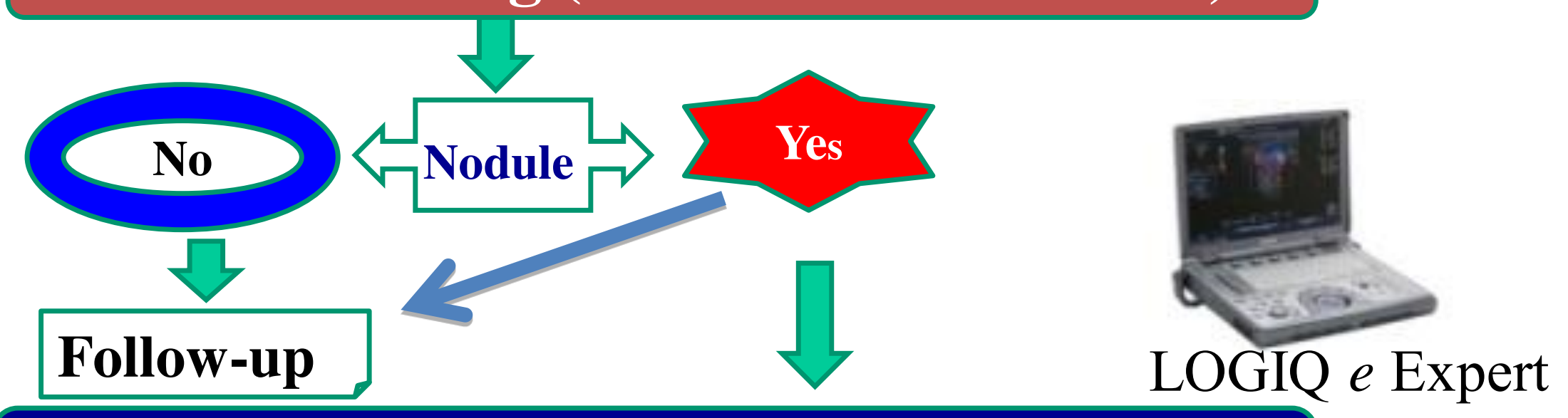

Secondary Screening

Precise US examination, Blood and Urine analysis

HIVISION Ascendus

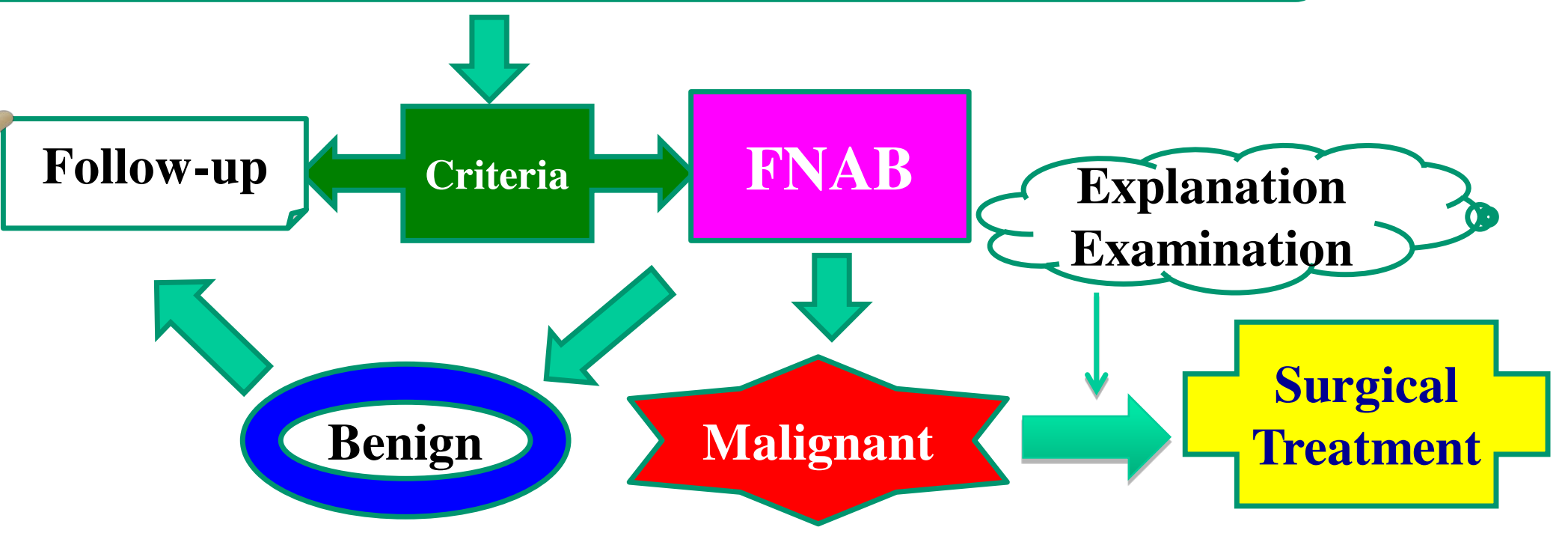

Fig. 10 


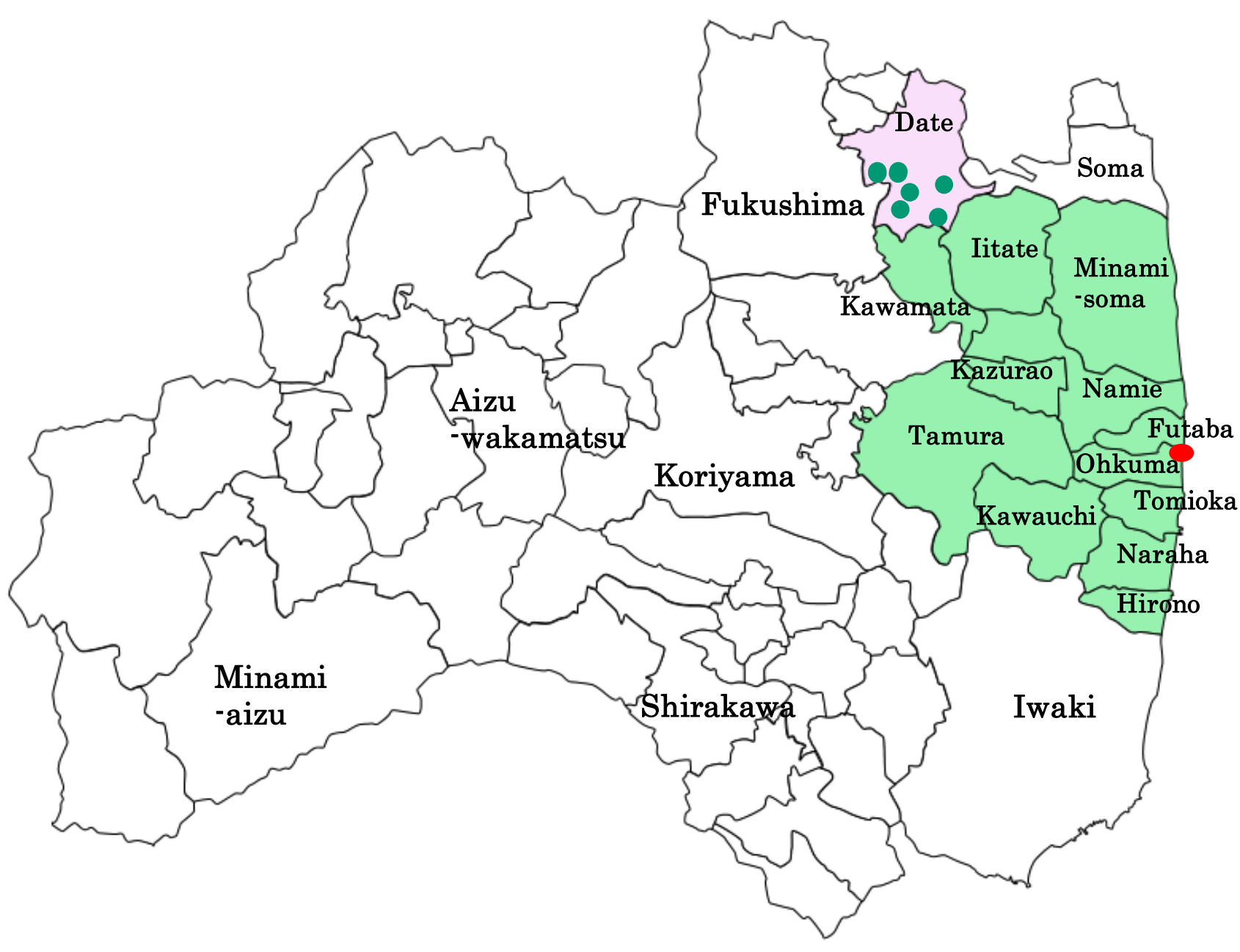

Residents of all ages living in the government-specified evacuation zone ( participated in the comprehensive health checkup.

Residents living in evacuation-recommended specific points in Date City ( o ) also took part in the comprehensive health checkup.

The size of the target cohort is 210,189 as of 31 March 2011. 


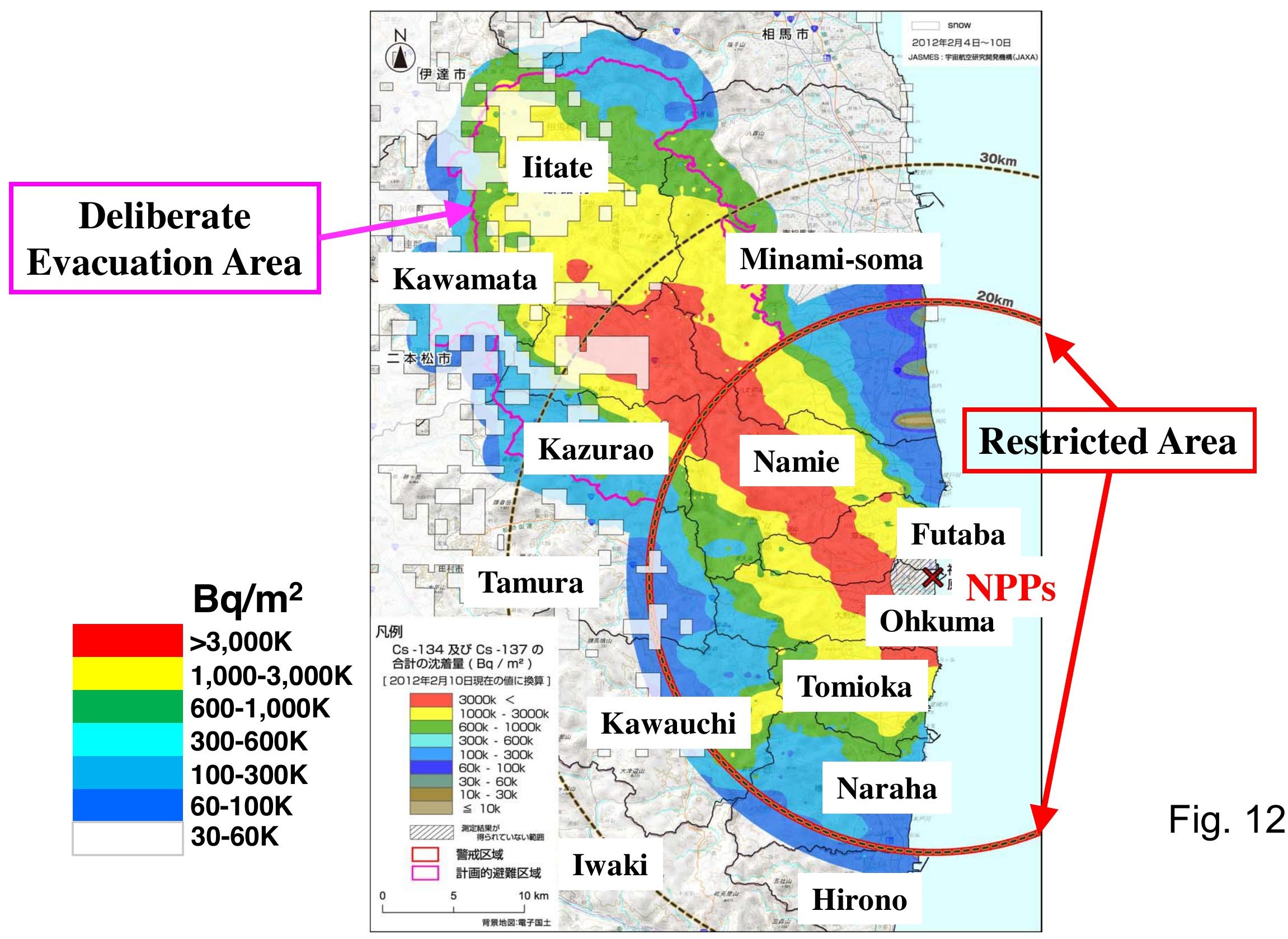

